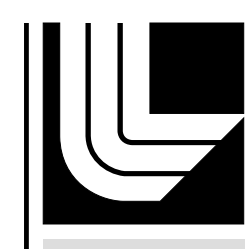

LAWRENCE LIVERM ORE NATIONAL LABORATORY

Development of MMC Gamma Detectors for Nuclear Analysis

C. R. Bates, C. Pies, S. Kempf, L. Gastaldo, A. Fleischmann, C. Enss, S. Friedrich

July 17,2013

Low Temperature Detectors 15

Pasadena, CA, United States

June 24, 2013 through June 28, 2013 
This document was prepared as an account of work sponsored by an agency of the United States government. Neither the United States government nor Lawrence Livermore National Security, LLC, nor any of their employees makes any warranty, expressed or implied, or assumes any legal liability or responsibility for the accuracy, completeness, or usefulness of any information, apparatus, product, or process disclosed, or represents that its use would not infringe privately owned rights. Reference herein to any specific commercial product, process, or service by trade name, trademark, manufacturer, or otherwise does not necessarily constitute or imply its endorsement, recommendation, or favoring by the United States government or Lawrence Livermore National Security, LLC. The views and opinions of authors expressed herein do not necessarily state or reflect those of the United States government or Lawrence Livermore National Security, LLC, and shall not be used for advertising or product endorsement purposes. 
C.R. Bates · C. Pies · S. Kempf · L.

Gastaldo - A. Fleischmann - C. Enss · S.

Friedrich

\title{
Development of MMC Gamma Detectors for Nuclear Analysis
}

Received: date / Accepted: date

\begin{abstract}
Non-destructive assay (NDA) of nuclear materials would benefit from gamma detectors with improved energy resolution in cases where line overlap in current Ge detectors limits NDA accuracy. We are developing metallic magnetic calorimeter (MMC) gamma-detectors for this purpose by electroplating 150 $\mu \mathrm{m}$ thick $\mathrm{Au}$ absorbers into microfabricated molds on top of $\mathrm{Au}: \mathrm{Er}$ sensors. Initial tests under non-optimized conditions show an energy resolution of $200 \mathrm{eV}$ FWHM at $60 \mathrm{keV}$. Monte Carlo simulations illustrate that this resolution is starting to be sufficient for direct detection of ${ }^{242} \mathrm{Pu}$ in plutonium separated from spent nuclear fuel.
\end{abstract}

Keywords MMC · gamma ray

\section{Introduction}

One of the primary tools used in nuclear safeguards to verify the operating history of a nuclear reactor is to compare the operators declaration to spent fuel characteristics. This is typically done using ratios of high intensity gamma ray lines with a high purity germanium (HPGe) detector. This method is becoming less reliable as advances in materials engineering make it possible to get more energy out of a fuel assembly before failure. As the fuel assembly is irradiated for longer periods of time the correlation of the high intensity gamma ray lines to fuel characteristics weakens. In addition, high burn-up produces increasing amounts of ${ }^{242} \mathrm{Pu}$, which can currently only be measured indirectly ${ }^{3}$. If the ratios of all $\mathrm{Pu}$ isotopes could be determined more accurately than what is possible with HPGe detectors,

C.R. Bates

Lawrence Livermore National Laboratory

7000 East Ave. L-188 Livermore, CA 94550, USA

Tel.: +1-925-424-6763

E-mail: bates26@1lnl.gov 


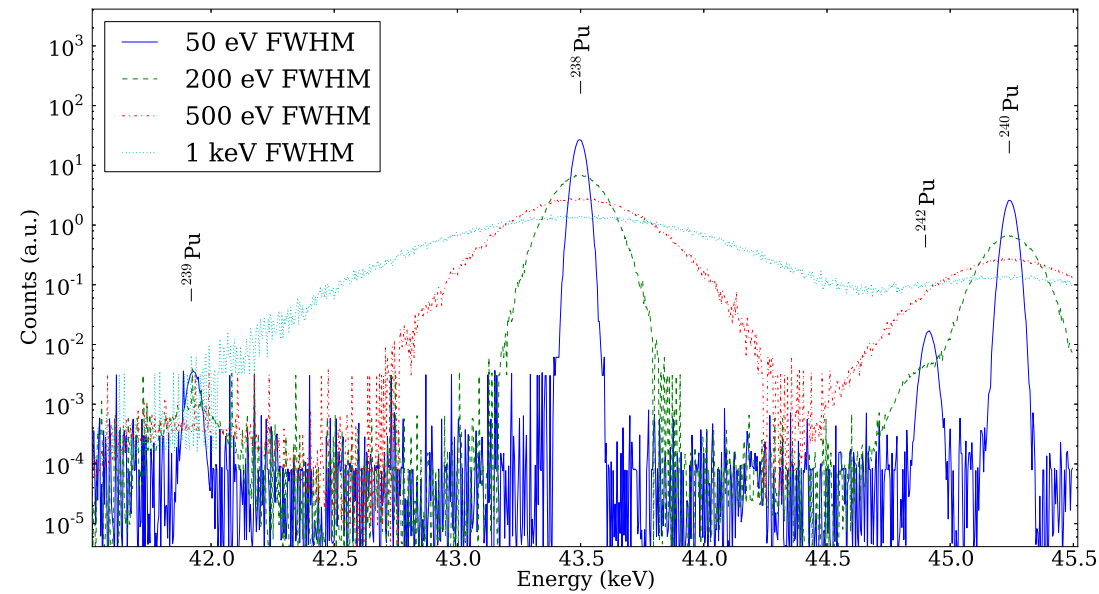

Fig. 1 Geant4 Simulation of Pu gamma ray lines near $40 \mathrm{keV}$ for different detector resolution's, assuming a Pu point source and full separation of $\mathrm{Pu}$ from the fission and activation products of the spent fuel. (color figure online)

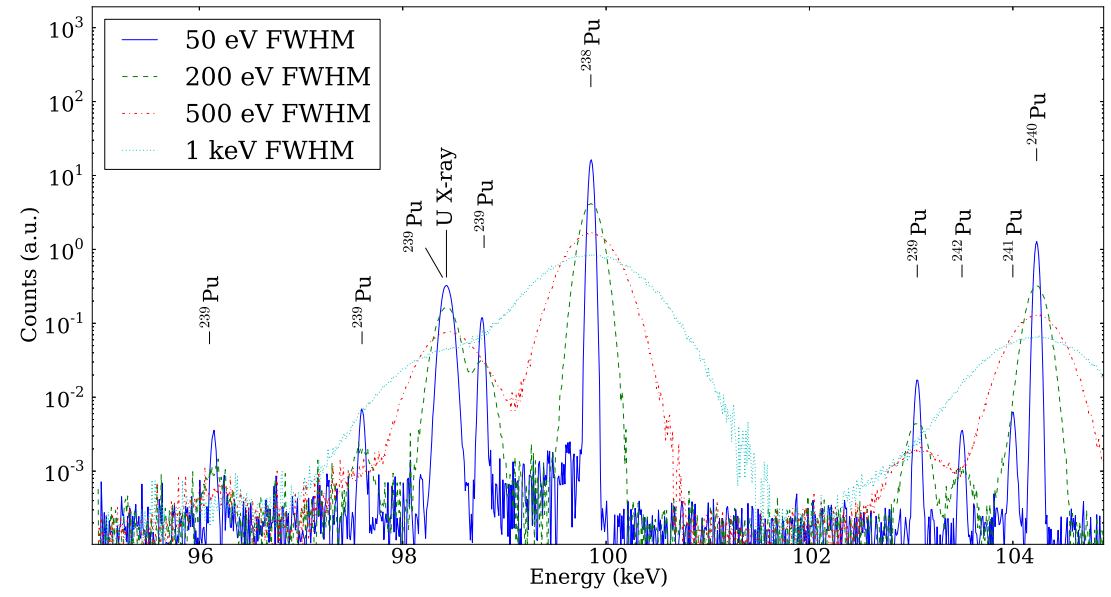

Fig. 2 Geant4 Simulation of Pu gamma ray lines near $100 \mathrm{keV}$ for different detector resolution's, assuming a Pu point source and full separation of $\mathrm{Pu}$ from the fission and activation products of the spent fuel. (color figure online)

better constraints could be placed on initial fuel enrichment and reactor operating history. This makes the development of high-resolution MMC gamma detectors desirable for use in this application.

\section{Direct Measurement of ${ }^{242} \mathrm{Pu}$ in spent fuel}

In order to measure the different $\mathrm{Pu}$ isotopes it is currently necessary to chemically separate the $\mathrm{Pu}$ from other metals. This is already common for routine mass 
spectroscopy and is also a standard part of fuel reprocessing. The separated $\mathrm{Pu}$ is typically deposited onto a thin $\mathrm{Al}$ planchet to minimize the scattering in the source and placed in front of the detector outside of the cryostat.

We have performed Geant4 Monte Carlo simulations to determine the resolution requirements of our detector ${ }^{5}$. As an input source we used the program ORIGEN-ARP to generate the expected $\mathrm{Pu}$ content for a fuel assembly with a typical irradiation profile for a modern pressurized water reactor. In order to simplify the simulation was assumed a point source geometry and that the $\mathrm{Pu}$ was perfectly seperated from other elements. We focused on the regions around 40 $\mathrm{keV}$ and $100 \mathrm{keV}$, since they contain gamma rays from all the relevant $\mathrm{Pu}$ isotopes and the proximity of the lines enables ratio measurements with a simple correction for efficiency.

Figure 1 shows the simulated spectrum from this area of interest with several different detector resolutions. The $1 \mathrm{keV} \mathrm{FWHM} \mathrm{spectra} \mathrm{is} \mathrm{typical} \mathrm{of} \mathrm{a} \mathrm{commer-}$ cial coaxial HPGe detector while the $500 \mathrm{eV}$ FWHM is typical of a thin planar HPGe optimized for low energy spectroscopy. The $200 \mathrm{eV} \mathrm{FWHM} \mathrm{spectrum}$ shows the limit at which the ${ }^{242} \mathrm{Pu}$ line at $44.8 \mathrm{keV}$ can be resolved, which is comparable to the best MMC spectrum in this work. Finally the $50 \mathrm{eV} \mathrm{FWHM} \mathrm{is}$ comparable to what is theoretically achievable in an optimally designed MMC that would have appreciable efficiency at $40 \mathrm{keV}$. Based on statistics, we estimate that a resolution of $75 \mathrm{eV} \mathrm{FWHM}$ is required to determine the $\mathrm{Pu}-242$ content to $1 \%$ precision, because the interfering $\mathrm{Pu}-240$ line is roughly 100 times stronger and separated by only $300 \mathrm{eV}^{6}$. This precision depends on the $\mathrm{Pu}-242 / \mathrm{Pu}-240$ ratio and the Compton background level, which may be higher than in Figure 1 because of the simplifying assumptions made in the simulations.

Figure 2 shows the simulated spectra for the same four detectors in the 100 $\mathrm{keV}$ region, which is widely used for $\mathrm{Pu}$ analysis ${ }^{4}$. Again, an MMC energy resolution of $200 \mathrm{eV}$ starts to separate the individual $\mathrm{Pu}$ emissions, although it may be more difficult to measure ${ }^{242} \mathrm{Pu}$ in this region even with $50 \mathrm{eV} \mathrm{FWHM}$. This is because the line is an order of magnitude weaker and the secondary $\mathrm{Pu} \mathrm{K} \alpha 1$ $\mathrm{X}$-ray fluorescence at $103.75 \mathrm{keV}$ can provide strong interference in concentrated $\mathrm{Pu}$ samples.

\section{Gamma-ray measurements of ${ }^{241} \mathrm{Am}$}

In order to demonstrate the feasibility of the $\mathrm{Pu}$ measurement with an MMC we installed an ${ }^{241} \mathrm{Am}$ source in front of a Heidelberg maXs-200 MMC in a $18 \mathrm{mK}$ dilution fridge operated at the Kirchhoff Institute for Physics ${ }^{7}$. This design uses a $\mathrm{Au}$ :Er sensor deposited on top of a $0.5 \mathrm{~mm} \times 2 \mathrm{~mm}$ meander of $\mathrm{Nb}$, which is used to both apply the field and readout the signal. In order to be sensitive to hard X-rays there is a $150 \mu \mathrm{m}$ thick electroplated $\mathrm{Au}$ absorber on top of the $\mathrm{Au}$ :Er. This device was read out using a two-stage SQUID, model C6XS116 from Magnicon $\mathrm{GmbH}$. The pulses were saved using a 12-bit Gage data acquisition card. The raw pulses were then processed using an optimal filter routine. Despite wiring issues with the device that forced us to operate with approximately $10 \%$ of the designed magnetizing current it was still possible to achieve a resolution of $200 \mathrm{eV}$ at $60 \mathrm{keV}$ (Figure 4). This performance shows that it should be possible to directly measure the ${ }^{242} \mathrm{Pu}$ line using this device even in sub-optimal operating 


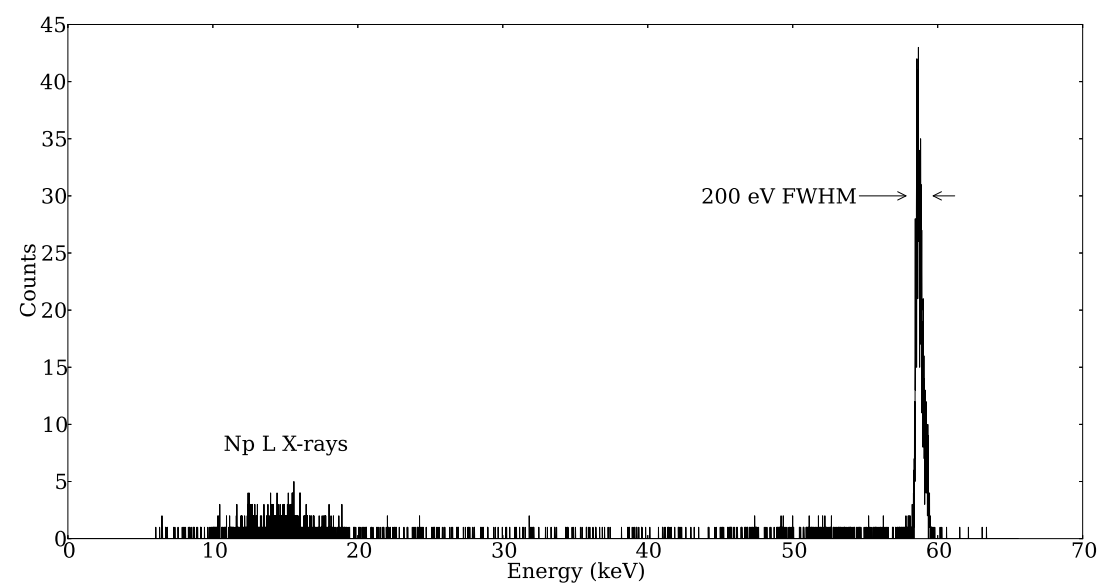

Fig. 3 Spectra of ${ }^{241}$ Am taken with a maXs-200 MMC.

conditions. Under optimal conditions this device has been shown to achieve an energy resolution of $60 \mathrm{eV} \mathrm{FWHM}$ at $60 \mathrm{keV}^{7}$. We are currently working on attaining similar resolution.

\section{Outlook}

In order to perform high accuracy plutonium analysis arrays of MMCs will be required to achieve good statistics. This is due to the long decay time, and therefore limited countrate of the devices, on the order of milliseconds and several hundred hertz respectively. In order for larger arrays to be feasible it is necessary for the individual pixels to have high yield. This is currently limited by the difficulty in removing the mold for the absorbers, made out of SU-8 photoresist. We are developing a process based on AZ-125 nXT photoresist which we have successfully spin coated to a thickness of $300 \mu \mathrm{m}$. This photoresist has been shown to produce thick molds for electroplating without the problems associated with SU- ${ }^{8}$. This should simplify the fabrication of high-yield MMC arrays with thick electroplated absorbers in the future.

Acknowledgements This work was funded by the U.S. Department of Energy grant LL12MagMicro-PD2Ja. This work was performed under the auspices of the U.S. Department of Energy by Lawrence Livermore National Laboratory under Contract DE-AC52-07NA27344.

\section{References}

1. C. Enss, Cryogenic Particle Detection, Topics Appl. Phys. 99, 151-217 (2005)

2. J. Svedkauskaite-LeGore, G. Rasmussen, C. Vincent, P. van Belle, and S. Abousahl, Importance of the impurity spectrum in nuclear materials for nu- 
clear safeguards, Proceedings of the International Safeguards Symposium Vienna, 533-539 (2006)

3. G. Bignan, W. Ruhter, H. Ottmar, A. Schubert, and C. Zimmerman. Plutonium Isotopic Determination By Gamma Spectometry: Recommendations for the ${ }^{242} \mathrm{Pu}$ content evaluation using a new algorithm. ESARDA BULLETIN, 28:16, (1998)

4. D. Reilly, N. Ensslin, H. Smith, Jr., and S. Kreiner,Passive Nondestructive Assay of Nuclear Materials , 221-267. National Technical Information Service, Springfield, VA (1991)

5. S. Agnostinelli et al., Geant4: a simulation toolkit, NIM A, 503:3, 250-303 (2003)

6. O.B. Drury, S.F. Terracol, and S. Friedrich, Quantifying the benefits of ultrahigh energy resolution for gamma ray spectrometry, phy. stat. sol. c 2, 14681479 (2005)

7. C. Pies, S. Schaefer, S. Heuser, S. Kempf, A. Pabinger, J.-P. Porst, P. Ranitsch, N. Foerster, D. Hengstler, A. Kampkoetter, T. Wolf, L. Gastaldo, A. Fleischmann, C. Enss, maXs: Microcalorimeter Arrays for High-Resolution X-Ray Spectroscopy at GSI/FAIR, J. Low Temp. Phys. 167, 269 (2012)

8. M. Staab, F. Greiner, M. Schlosser, and H.F. Schlaak, Applications of Novel High-Aspect-Ratio Ultrathick UV Photoresist for Microelectroplating, JMEMS Letters 20:4, 794-796 (2011) 